\title{
In vitro and In vivo Evaluation of Tablets Containing Meloxicam- PEG 6000 Ball-Milled Co-Ground Mixture
}

\author{
Mohamed Etman ${ }^{1}$, Mustafa Shekedef ${ }^{1}$, Aly Nada $^{2 *}$, Assem Ismail $^{1}$ \\ ${ }^{1}$ Department of Pharmaceutics, Faculty of pharmacy, Alexandria University, Alexandria, Egypt. \\ ${ }^{2}$ Department of Pharmaceutics, Faculty of Pharmacy, Kuwait University, Kuwait.
}

\begin{tabular}{l} 
ARTICLE INFO \\
\hline Article history: \\
Received on: $20 / 10 / 2016$ \\
Accepted on: $21 / 11 / 2016$ \\
Available online: $30 / 03 / 2017$ \\
\hline Key words: \\
Meloxicam, PEG, co- \\
grinding, dissolution, tablets, \\
in vitro, in vivo.
\end{tabular}

\begin{abstract}
This study aimed at a) preparing meloxicam (MLX) tablets containing ball-milled co-ground mixture with PEG $6000(1: 4)$; b) evaluating the relevant in vitro quality parameters and stability; and c) comparing the bioavailability of the developed tablets with that of a reference meloxicam tablet $\left(\mathrm{Mbc}^{\circledR}\right)$ in 6 human subjects. The dissolution rate of the prepared tablets was higher than that containing ball-milled or un-milled drug alone, as well as higher than four marketed meloxicam tablets. Upon storage for 12 months at $25 \pm 1^{\circ} \mathrm{C} / 60 \% \mathrm{RH}$, no remarkable changes in physical appearance of the prepared tablets, \% drug content, thickness, disintegration time and in dissolution rate were observed. The prepared meloxicam tablets showed higher bioavailability which was indicated by significant higher AUC and significant shorter $\mathrm{T}_{\max }$. The bioavailability of the developed test tablets was $126.45 \%$, relative to the marketed brand product (Mbc ${ }^{\circledR}$ tablets). Grinding of MXL with PEG 6000 resulted in a fast MLX release, which may provide rapid onset of action and allow also a reduction of required dose necessary to obtain the therapeutic effect. This, in turn, may further reduce the most common side effects observed with non-steroidal anti-inflammatory drugs (NSAIDs).
\end{abstract}

\section{INTRODUCTION}

Several factors, other than physicochemical properties of the drug, may influence the therapeutic efficacy of drugs from the dosage forms, such as the dissolution rate. It has been shown by many authors that, the dissolution rate of pure drugs can be altered significantly by the proper selection of formulation components as well as processing methods, e.g. (Blagden et al., 2007; Grau et al., 2000). Meloxicam (MLX) is one of the Cox II inhibitors and considered safer than other NSAIDs. However, the major problem with the drug is its very low solubility in biological fluids. The rate of dissolution can be increased by increasing the surface area of the drug by different methods of size reduction including grinding, co-grinding or solid dispersion methods. Moreover, the dissolution of a drug can also be influenced by the disintegration time of the tablets (Engelhardt $e t$ al., 1995). Rapid absorption may also reduce the frequency and severity of gastrointestinal disorders observed after oral

* Corresponding Author

Aly H. Nada, Department of Pharmaceutics, Faculty of Pharmacy,

Kuwait University, Kuwait. Email: alynada@hsc.edu.kw administration of certain drugs such as aspirin and tetracycline, by reducing the contact time in the gastrointestinal tract (Gibaldi 1991). In a previous study from this laboratory, MLX was formulated into co-ground mixtures by ball/vibrational milling in presence of hydrophilic carriers. It was found that grinding of crystalline meloxicam together with a semi-crystalline polymer PEG 6000 led to a drastic reduction in particle size and crystallinity of MLX, as well as enhanced dissolution profile. The co-ground mixture consisting of MLX: PEG (1: 4) using ball mill was found to have superior dissolution compared to all other coground mixtures (Etman et al., 2015). Therefore, the aims of this study were: a) to prepare Meloxicam tablets containing ball-milled co-ground mixture with PEG $6000(1: 4)$; b) to evaluate the relevant in vitro quality parameters of the finished tablets such as drug content, hardness, friability, disintegration time, thickness and dissolution; c) to compare the dissolution profile with three marketed Meloxicam tablets; d) to test its stability at $25 \pm 1^{\circ} \mathrm{C} /$ $60 \% \mathrm{RH}$ for 12 months; and finally e) to compare the bioavailability of the developed tablets with that of a marketed meloxicam tablets $\left(\mathrm{Mbc}^{\circledR}\right)$, using 6 male human subjects in a crossover design. 


\section{EXPERIMENTAL}

\section{Materials}

Avicel $^{\circledR}$ (FMC, USA), Polyplasdone ${ }^{\circledR}$ crospovidone (ISP, USA), Aerosil ${ }^{\circledR} \quad$ (Evonik, Germany), magnesium stearate (Siemsgluss \& Sohn GmbH \& Co., India), Mbil ${ }^{\circledR}$ tablets (Medical Union pharmaceuticals, Abu-Sultan, Ismailia, Egypt.), Mbc ${ }^{\circledR}$ tablets (Boehringer Ingelheim, Germany) and Anti ${ }^{\circledR}$ (ADWIA Co.S.A.E., $10^{\text {th }}$ of Ramadan City, Egypt), clear transparent hard gelatin capsules, size (0) were kindly supplied by Pharco Pharmaceuticals Co. (Alexnadria , Egypt), HPLC grade methanol and acetonitrile (Gliwiceul, Sowinskiego, Poland), and HPLC grade phosphoric acid and potassium dihydrogen phosphate (Fisher, USA). All materials were used as received from their sources without any further treatment.

\section{Apparatus}

Single punch tablet machine, $12 \mathrm{~mm}$ flat-faced punches and hardness tester, type TB24 (Erweka, GmbH, Heusenstamm, Germany), micrometer (Moore and Wright Ltd. Britain Tool, Sheffield, UK), differential scanning calorimeter (Pyris 6 DSC, Perkin Elmer, USA) and a friabilator (Erweka, Germany), FT-IR (Thermo Fisher Scientific, Inc., Waltham, MA, USA), scanning electron microscope (LEO , 435 VP , UK), XRD ( Rigaku Demki, Rint-2500VL, Tokyo, Japan), a reversed phase C-18 Perkin Elmer

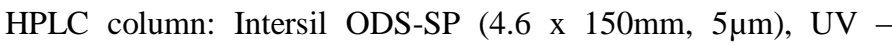
detector jENWAY 6305 (England), a loop injector equipped with a $25 \mu \mathrm{L}$ loop and vortex (VM-300, U.S.A).

\section{Methods}

\section{Preparation of meloxicam- PEG 6000 tablets}

Calculated amount of meloxicam ball-milled co-ground mixture with PEG 6000 in 1:4 ratio (Etman et al., 2015), equivalent to $15 \mathrm{mg}$ of the drug, was employed. Co-ground

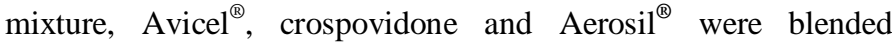
thoroughly in a mortar with pestle for 10 minutes to achieve a homogenous mixture. The powder blend (Table 1) was then lubricated with magnesium stearate $(0.5 \% \mathrm{w} / \mathrm{w})$ for additional 3 minutes and this lubricated blend was compressed into tablets using $12 \mathrm{~mm}$ flat-faced round tooling on a single punch tablet machine.

Table 1: Ingredients of the prepared meloxicam tablets.

\begin{tabular}{|c|c|c|c|}
\hline Ingredients (mg) & $\begin{array}{c}\text { Un- } \\
\text { milled } \\
\text { MLX }\end{array}$ & $\begin{array}{l}\text { Milled } \\
\text { MLX } \\
\text { alone } \\
\text { (BM) }\end{array}$ & $\begin{array}{c}\text { MLX : PEG } 6000 \\
(1: 4) B M\end{array}$ \\
\hline Meloxicam & 15 & 15 & $75 \mathrm{mg} \operatorname{mix}=15 \mathrm{mg} \mathrm{MLX}$ \\
\hline Avicel $^{\circledR}$ & 160 & 160 & 100 \\
\hline Crosspovidone & 20 & 20 & 20 \\
\hline Aerosil $^{\circledR}$ & 4 & 4 & 4 \\
\hline Magnesium stearate & 1 & 1 & 1 \\
\hline Final weight (mg) & 200 & 200 & 200 \\
\hline
\end{tabular}

Furthermore, the same amount of Meloxicam ball-milled co-ground mixture with PEG (1:4) and other ingredients used in the preparation of MLX tablets (except magnesium stearate) were mixed and filled into empty hard gelatin capsules to study the effect of compression, used in tablet manufacture, on drug release.

\section{In vitro evaluation of the prepared $M L X$ tablets Drug content}

Ten Tablets were finely ground in a mortar and the amount of powder equivalent to $15 \mathrm{mg}$ of MLX was taken and dissolved in $100 \mathrm{ml}$ phosphate buffer $\mathrm{pH}$ 7.4. Aliquots were filtered through $0.2 \mu \mathrm{m}$ Millipore filter and assayed spectrophotometrically at $362 \mathrm{~nm}$.

\section{Uniformity of Weight}

Twenty tablets were weighed collectively and individually, and the average weight $( \pm \mathrm{SD})$ was calculated.

\section{Hardness test}

The hardness test was performed by Erweka hardness tester using 5 tablets, and the average force of fracture $( \pm \mathrm{SD})$ was recorded in $\mathrm{Kg} / \mathrm{cm}^{2}$.

\section{Tablet thickness}

The thickness of 5 tablets was measured using a micrometer. The mean thickness $( \pm \mathrm{SD})$ was calculated.

\section{Friability test}

Twenty tablets were carefully de-dusted, weighed, loaded in the friability tester, and rotated at $25 \mathrm{rpm}$ for 15 minutes. Tablets were removed from drum, de-dusted and accurately weighed. If obviously cracked, cleaved or broken tablets are present in the tablets sample, the sample fails. The percentage of weight loss was calculated using the following equation:

$$
\% \text { Friability }=[(\mathrm{W} 1-\mathrm{W} 2) \times 100] / \mathrm{W} 1
$$

Where: $\mathrm{W} 1$ = weight of tablet before test (initial weight).

$\mathrm{W} 2$ = weight of tablet after test (final weight).

The results should be less than $1 \%$ (USP 2006).

\section{Disintegration time test}

The disintegration time of the developed MLX tablets was determined by USP disintegration apparatus using one liter distilled water kept at $37 \pm 0.5{ }^{\circ} \mathrm{C}$ as disintegrating medium. The average time required for complete dispersion of 6 tablets was calculated $( \pm \mathrm{SD})$.

\section{Dissolution test}

The in-vitro dissolution study was carried out in the USP type II (paddle) dissolution apparatus using $900 \mathrm{ml}$ of phosphate buffer $\mathrm{pH} 7.4$ as the dissolution medium at $37 \pm 0.5^{\circ} \mathrm{C}$. The speed of the paddle was set at $50 \mathrm{rpm}$ and $5 \mathrm{ml}$ of the dissolution medium was withdrawn for analysis and replaced with the same volume of fresh dissolution medium. The sample was filtered and assayed spectrophotometrically at $362 \mathrm{~nm}$.

Dissolution rate of the prepared tablets was compared with that of 3 marketed tablet brands of MLX (15 mg each); 
$\mathrm{Mbil}^{\circledR}, \mathrm{Mbc}^{\circledR}$ and $\mathrm{Anti}^{\circledR}$ under the same dissolution conditions described above.

The prepared MLX capsules were also tested for dissolution under the same conditions described before. Each formulation was tested in triplicate and the mean values were calculated.

\section{Scanning electron microscopy (SEM)}

Images by SEM were performed to visualize the reduction in particle size of MLX by co-grinding. Prior to examination, samples were gold-coated under vacuum and scanned at $25 \mathrm{kV}$, using 5000x magnification.

\section{Fourier transform infra-red spectroscopy (FT-IR):}

Infra-red spectra of untreated MLX, PEG, and the coground mixture were determined, where $2 \mathrm{mg}$ sample was mixed with $200 \mathrm{mg}$ potassium bromide, ground into fine powder, and then compressed into a disc using a hydraulic press. Each disc was scanned over the region of $500-4000 \mathrm{~cm}^{-1}$ and the resolution was $4 \mathrm{~cm}^{-1}$. The characteristic bands were recorded for all tested samples.

\section{Differential scanning calorimetry (DSC)}

The DSC thermograms were traced for each of the untreated MLX, PEG, and the ground mixture. The powdered sample $(5 \mathrm{mg}$ ) was hermetically sealed in aluminum pans and heated at a constant rate of $10^{\circ} \mathrm{C} / \mathrm{min}$, over a temperature range of $25^{\circ} \mathrm{C}$ to $200^{\circ} \mathrm{C}$. Indium standard was used to calibrate the DSC temperature and enthalpy scale under constant purging of dry nitrogen at $30 \mathrm{ml} / \mathrm{min}$.

Characterization of meloxicam tablets by $X$ - ray diffraction (XRD)

XRD analysis of untreated drug, PEG 6000, the ground mixture, and the prepared MLX tablets were performed. Samples were irradiated with monochromatized $\mathrm{Cu} \mathrm{K \alpha}$ radiation $\left(1.542^{\circ} \mathrm{A}\right)$ and analyzed between 2 and $40^{\circ}$. The voltage and current used were $40 \mathrm{kV}$ and $30 \mathrm{~mA}$, respectively. The chart speed was 10 $\mathrm{mm} / \mathrm{sec}$.

\section{Stability study}

Stability study was carried out by storing the prepared tablets in amber colored screw capped glass bottles which were placed in a thermostatically controlled incubator at $25 \pm 1^{\circ} \mathrm{C} / 60 \%$ RH over a period of 12 months.

At intervals of 3 months, the stored tablets were subjected to evaluation for any physical changes, in addition to analysis of drug content, dissolution and XRD. Dissolution test was performed in phosphate buffer at $\mathrm{pH} 7.4$ as previously mentioned.

\section{In vivo study \\ HPLC method of analysis}

The MLX concentration in blood was determined by a validated HPLC method, as described below. The mobile phase consisted of acetonitrile - $20 \mathrm{mM}$ potassium dihydrogen phosphate (60:40\%, v/v, pH 3.5). Flow rate of degassed mobile phase was 1.2 $\mathrm{ml} / \mathrm{min}$ (isocratic conditions) at room temperature. Injected sample volume was $25 \mu \mathrm{L}$ and UV detection was set at a wavelength of $355 \mathrm{~nm}$ (Velpandian et al., 2000).

\section{Calibration and sample preparation}

A primary stock standard solution of $\operatorname{MLX}(0.1 \mathrm{mg} / \mathrm{mL})$ was prepared in HPLC - grade methanol to obtain a series of working standard solutions of 100, 200, 300, 500, 1000, 2000, and $5000 \mathrm{ng} / \mathrm{mL}$. A stock solution of piroxicam (PIR) $(0.1 \mathrm{mg} / \mathrm{mL})$ was also prepared in methanol as the internal standard (IS) solution. Stock solutions were stored at $-20^{\circ} \mathrm{C}$ and working standard solutions used to generate the calibration curve were freshly prepared from stock solutions for each analysis. Blank human plasma from different subjects was collected, and used for preparing the standard samples for calibration curve. Three different MLX standard solutions (100, 500, and $2000 \mathrm{ng} / \mathrm{mL}$ ) were used for analytical method validation. For construction of the calibration curve, $50 \mu \mathrm{L}$ of MLX working standard solutions (ranging from 100 to $5000 \mathrm{ng} / \mathrm{mL}$ ) were freshly prepared and mixed with $250 \mu \mathrm{L}$ of blank human plasma, pre-thawed at room temperature, plus $20 \mu \mathrm{L}$ of PIR (internal standard) and $200 \mu \mathrm{L}$ of acetonitrile acidified with $\mathrm{H}_{3} \mathrm{PO}_{4}(0.1 \%$, v/v), vortexed for 20 seconds, and centrifuged for 15 minutes at $3000 \mathrm{rpm}$. The clear supernatants were collected in culture tubes and filtered through $0.2 \mu \mathrm{m}$ Millipore filter.

For measurement of meloxicam concentrations in plasma samples, $250 \mu \mathrm{L}$ of plasma was mixed with $20 \mu \mathrm{L}$ of the internal standard plus $200 \mu \mathrm{L}$ of acetonitrile acidified with $\mathrm{H}_{3} \mathrm{PO}_{4} 0.1 \%$ $(\mathrm{v} / \mathrm{v})$, and treated in the same way for calibration samples mentioned above (Velpandian et al., 2000; Ji et al., 2005).

\section{Analytical method validation}

Selectivity of the assay was assessed by analyzing blank human plasma to evaluate interference of endogenous matrix of plasma around the retention times of both MLX and the IS. MLX plasma peak was identified based on retention time and UV spectra of the reference standard. MLX concentrations in plasma samples were quantified according to the plasma calibration curves for which seven MLX concentrations (100, 200, 300, 500, 1000, 2000, and $5000 \mathrm{ng} / \mathrm{mL}$ ) were used to establish the least square linear regression of the curve:

$$
\mathrm{y}=\mathrm{ax}+\mathrm{b}
$$

Where " $x$ " is the concentrations of MLX, " $y$ " is the peak area ratio of MLX to IS, "a" and "b" represent the slope and yintercept of the curve, respectively. According to the pharmacopeial recommendations (USP 2011), the limit of detection (LOD) is defined as the concentration that has a signal to - noise ratio of $3: 1$, while for limit of quatitification (LOQ), the ratio considered is $10: 1$. The limit of quantification (LOQ) was determined based on calibration curves using the formula:

$$
\mathrm{LOQ}=10 \times \sigma / \mathrm{S}
$$


Where " $\sigma$ " is the standard deviation (SD) of the y-intercepts for the regression lines, and " $\mathrm{S}$ " is the mean slope of the calibration curves. An acceptance criterion for LOQ was defined as precision less than $15 \%$ (coefficient of variation; $\mathrm{CV}$ ) and accuracy within \pm $20 \%$ of the nominal concentration with repeated analyses.

The within-day (Intra-day) and the between-day (inter-day) precision and accuracy for the method were studied at three concentration levels (100, 500, and $2000 \mathrm{ng} / \mathrm{mL})$ using three replicate determinations for each concentration within one day and repeated on three consecutive days, respectively. Relative difference of the estimated concentrations was expressed as a percentage of the CV. Intra- and inter-day accuracy expressed as bias, which was determined by calculating the percentage difference between the estimated value and nominal value of MLX:

$\{$ (estimated value - nominal value $) /$ nominal value $\} \times 100$ Absolute recovery of MLX was measured by comparing the peak area of plasma samples pre-spiked with 10, 500, and $2000 \mathrm{ng} / \mathrm{mL}$ MLX with corresponding concentrations of MLX in the mobile phase. Each assay was conducted in triplicate and the obtained results were statically analyzed using one-way analysis of variance (ANOVA) followed by Tukey-Kramer multiple comparisons test. P-values $<0.05$ were considered statistically significant.

\section{Study design}

Before starting the in vivo study, the protocol was approved by the Ethics Committee, Faculty of Pharmacy, Alexandria University. The study was carried out in two - periods, single - dose, crossover, randomized order. Six healthy male volunteers (24-28 years old and 70-90 kg) participated in this study. The volunteers were informed about the purpose, duration, and risks of the study, and they were requested to sign a written informed consent. The subjects were given the developed meloxicam tablets (test product) and $\mathrm{Mbc}^{\circledR} 15 \mathrm{mg}$ tablet (reference product) in a randomized order, separated by two weeks washout period. Each subject was instructed to abstain from all medications for one week before starting the study or during the study weeks. The subjects were fasted 12 hs before and 4 hs after the administration of tablets. Each subject received the prepared tablet and reference product with $250 \mathrm{ml}$ of water. Venous blood samples $(5 \mathrm{ml})$ were withdrawn at different time intervals of 0,1 , 2, 3, 4, 5, 6, 8, 10, 12 and 24 hrs post dose administration and were collected in tubes containing EDTA. Precipitation of plasma proteins was performed by addition of $0.5 \mathrm{ml}$ acetonitrile followed by agitation mechanically on a vortex for $30 \mathrm{sec}$. The blood samples were centrifuged at $3000 \mathrm{rpm}$ for $15 \mathrm{~min}$ and plasma was separated and frozen at $-20{ }^{\circ} \mathrm{C}$ until analyzed.

\section{Pharmacokinetic (PK) evaluation}

Plasma concentration - time curves were used for PK analysis of the prepared MLX tablets and the reference product. Area under the curve (AUC) from time 0 to 24 hours $\left(\mathrm{AUC}_{0-24}\right)$ was estimated by the linear trapezoidal method, while AUC from time 0 to infinity ( $\mathrm{AUC}_{0 \text {-inf }}$ ) was obtained by adding $\mathrm{C}_{24} / \mathrm{k}_{\mathrm{el}}$ ratio to the $\mathrm{AUC}_{0-24}$, where $\mathrm{C}_{24}$ and $\mathrm{k}_{\mathrm{el}}$ represent the plasma concentration of meloxicam at 24 hours postdose and the elimination constant, respectively. Maximum concentration $\left(\mathrm{C}_{\max }\right)$ and the time to achieve $\mathrm{C}_{\max }\left(\mathrm{T}_{\max }\right)$ were obtained from direct visual inspection of plasma concentration versus time curves. Other relevant pharmacokinetic parameters including half life $\left(t_{1 / 2}\right)$, elimination rate constant $\left(\mathrm{K}_{\mathrm{el}}\right)$, area under the first moment curve (AUMC) and mean residence time (MRT) were also computed. AUMC was obtained by plotting mean meloxicam plasma concentration multiplied by time versus time. MRT was calculated by dividing AUMC over $\mathrm{AUC}_{0-24}$ (Velpandian et al., 2000) and (Ji et al., 2005).

\section{RESULTS AND DISCUSSION}

\section{In vitro evaluation of the prepared meloxicam tablets}

The post compression parameters such as drug content, weight variation, hardness, friability, thickness, and disintegration time were acceptable. The drug content in various formulations varied between 99.55 and $101.15 \%$. Tablet weight varied between 199.5 and $201 \mathrm{mg}$ and the hardness varied between 4.5 and $5 \mathrm{Kg}$ / $\mathrm{cm}^{2}$. The thickness was in the range 4.07 to $4.24 \mathrm{~mm}$ and disintegration time varied between 48 and $396 \mathrm{sec}$.

Friability is closely related to tablet hardness and is designed to evaluate the ability of the tablet to withstand abrasion in packaging, handling and shipping as friction and shock are the forces that most often cause tablet to chip, cap or break. Friability of all formulations was less than $1 \%$, which indicates a good mechanical resistance of the tested tablets.

Tablets containing co-ground mixture disintegrated rapidly (48 $\pm 1.49 \mathrm{sec}$ ), while those contained unmilled or milled MLX alone exhibited longer disintegration time (396 $\pm 1.5 \mathrm{sec}$ and $225 \pm 1.69 \mathrm{sec}$ respectively). Co-grinding of MLX with PEG 6000 would be expected to increase the wettability, decrease particle size and crystallinity of the drug that resulted in a reduction of disintegration time.

\section{Dissolution study}

The dissolution rate of MLX from the tested tablet formulation, containing MLX-PEG co-ground mixture, and three different brand products are shown in Fig. 1.

The dissolution profile of tablets containing co-ground mixture with PEG 6000 (1:4) was higher than that containing unmilled or milled drug alone. Also, dissolution rate of tablet containing co-ground mixture of MLX was higher than the other meloxicam tablet brands. This may be due to the use of crospovidone, which causes swelling to $4-8$ folds in 10 seconds and due to particle size reduction and improved wettability by cogrinding technique. In addition to micronization, conversion of drug to amorphous form during the preparation might have also contributed to the increased dissolution rates observed with the coground MLX-PEG mixture. 


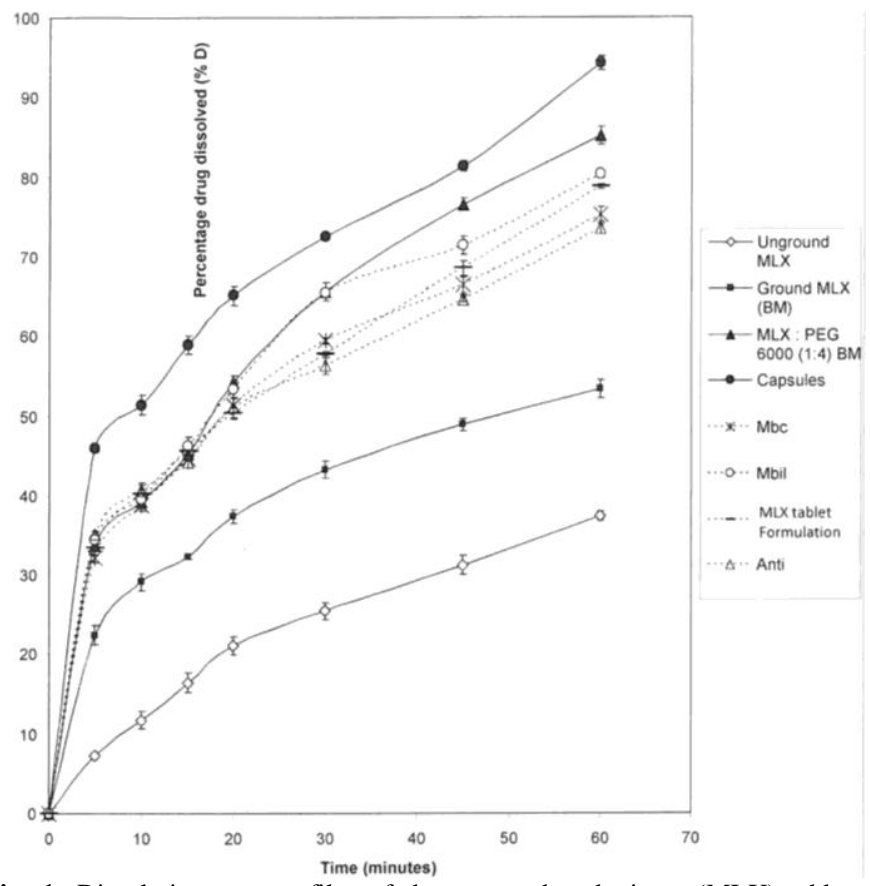

Fig. 1: Dissolution rate profiles of the prepared meloxicam (MLX) tablets, capsules, and the marketed meloxicam brand tablets, in comparison with the untreated MLX, ball milled MLX, and ball milled coground mixture.

\section{Scanning electron microscope (SEM)}

The surface morphology of unground MLX, ground MLX alone and its co-ground mixture with PEG (1:4 drug to polymer ratio) using ball mill were examined by SEM. Figures. 24 show selected SEM images of representative samples. Drug particles of meloxicam under scanning electron microscope appeared as crystals having the width of about $7 \mu \mathrm{m}$ and a length of about $21 \mu \mathrm{m}$ (Fig. 2).

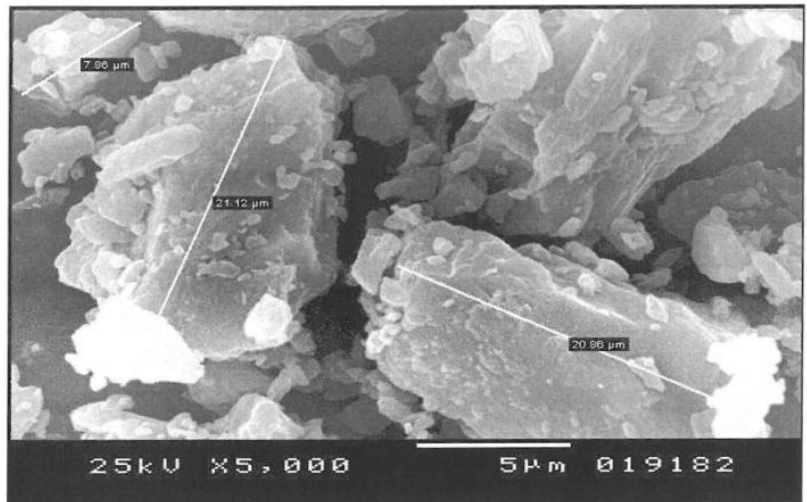

Fig. 2: SEM image of unmilled meloxicam.

Grinding of MLX alone in ball mill resulted in a reduction in particle size (3.5-10.5 $\mu \mathrm{m})$ (Fig. 3). Co-grinding of MLX with the carrier PEG in a ratio of 1:4 using ball milling technique resulted in a remarkable reduction in particle size to 1.39-2.14 $\mu \mathrm{m}$ width and 2.52-3.59 $\mu \mathrm{m}$ length (Fig. 4). The dimensions measured from the co-ground mixture are the dimensions of particles that constitute a mixture of the drug adhered or fused in the carrier matrix and are not entirely made of pure drug. This would mean that the particle size of the co-ground drug is much smaller than that of the milled drug alone. The reduction in particle size evidenced by the SEM, in addition to other findings obtained in the IR, XRD and DSC studies hereafter, would explain the observed enhancement in drug dissolution.

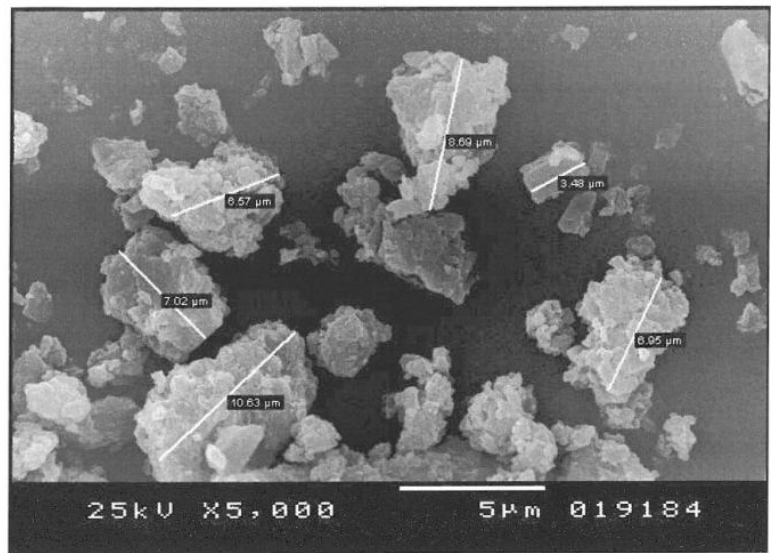

Fig. 3: SEM image of milled meloxicam alone using ball mill.

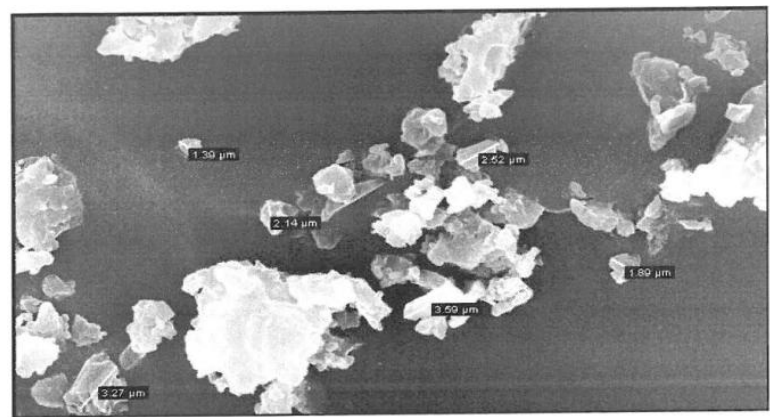

Fig. 4: SEM image of meloxicam with PEG 6000 in ratio 1:4 using co-grinding technique by ball mill.

\section{$X$ - ray diffraction $(X R D)$ study}

The powder XRD patterns of MLX, PEG 6000 and the mixtures thereof (Fig. 5), in addition to the prepared Meloxicam tablets (Fig. 6) were determined. The diffraction pattern of the pure drug showed its highly crystalline nature, as indicated by the numerous distinctive peaks at 10.30, 10.38, 10.87, 13.26, 14.69, $16.22,17.75,20.43,23.44,24.43,25.49,26.42,27.58,29.23$, $31.90,33.81,36.89,39.50,43.19,44.65$ and $47.67^{\circ}$. XRD pattern of PEG 6000 alone exhibited two high intensity peaks at $19^{\circ}$ and $23^{\circ}$. The lack of the numerous distinctive peaks of the drug in the co-ground mixture could demonstrate that a major quantity of the drug was incorporated in the solid-state carrier matrix in an amorphous structure. The results above indicate that co-grinding of meloxicam with PEG 6000 using ball-mill caused some changes that may include size reduction (Figs. 2-4), reduced crystallinity, and / or conversion into amorphous form (Figs. 5\&6). Tablets prepared using this co-ground mixture along with some excipients produced a product with superior properties, compared to the existing marketed products containing meloxicam, as indicated from the bioavailability study hereafter. 


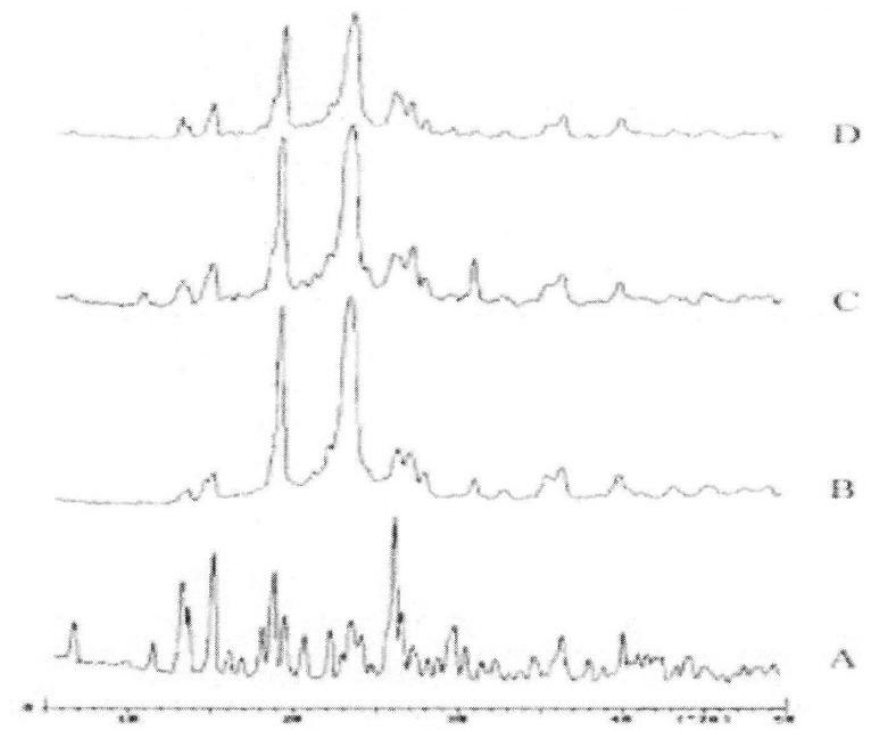

Fig. 5: Powder X-ray Diffraction Spectra of MLX (A), PEG 6000 (B), PM with PEG 6000 (1:4) (C), and Co-ground mixture with PEG 6000 (1:4) (D).

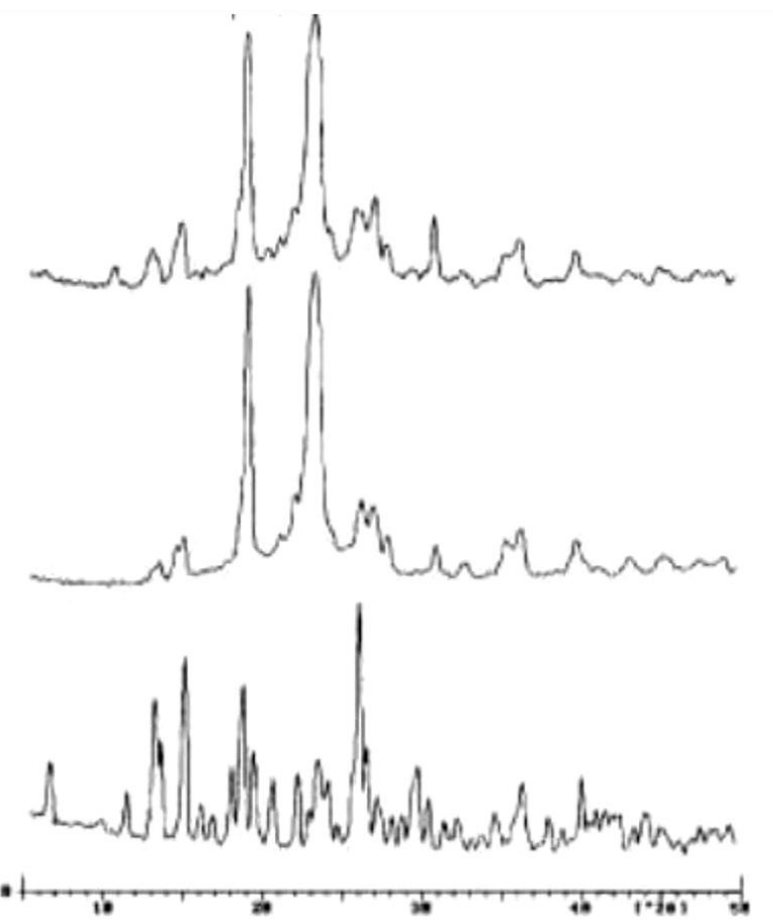

Fig. 6: XRD Patterns of Pure Meloxicam (A), PEG 6000 (B) and the prepared Meloxicam tablets (C).

\section{Infrared (FT-IR) study}

The interaction between the drug and the carrier often leads to identifiable changes in the FT-IR profile of the drug. FTIR spectra for MLX, PEG, and the co-ground mixture were performed (Fig. 7). FT-IR spectrum of MLX showed prominent peaks at 3291, 1620, 1552,1340, and $1180 \mathrm{~cm}-1$ resulting from stretching vibration bands of $\mathrm{N}-\mathrm{H}, \mathrm{C}=\mathrm{O}, \mathrm{C}-\mathrm{C}$, and two $\mathrm{S}=\mathrm{O}$, respectively. The spectrum of co-ground mixture exhibited a decrease in the intensities of $\mathrm{N}-\mathrm{H}$ and $\mathrm{S}=\mathrm{O}$ stretching vibration peaks of MLX that ranges from minor to significant changes. The reduction in peak intensities could indicate a sort of hydrogen bonding, a reduction in crystallinity and / or transformation to amorphous state of the drug, which may explain the better dissolution of the co-ground mixture, compared to the untreated drug. The reduction in peak intensities also would indicate the possibility of intermolecular hydrogen bonding via $\mathrm{N}-\mathrm{H}, \mathrm{S}=\mathrm{O}$ and $\mathrm{C}=\mathrm{N}$ groups of MLX and hydroxyl groups of PEG. In the low frequency region $\left(1000-400 \mathrm{~cm}^{-1}\right)$ of the spectrum of the coground mixture, the peaks characteristic of MLX were almost unchanged. This indicated that although the drug molecule is hydrogen bonded with the polymer, yet the overall symmetry of the molecule is not significantly affected.

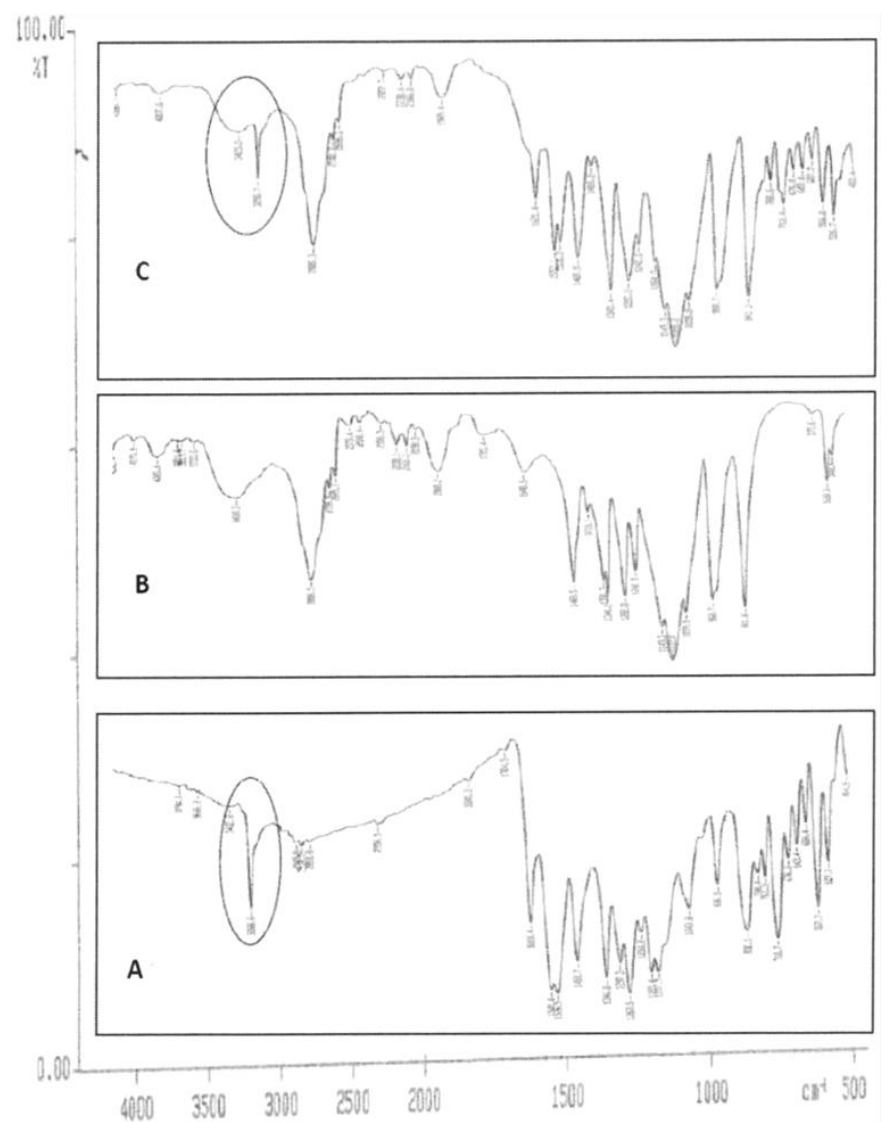

Fig. 7: FT-IR spectra of meloxicam ball milled co-ground mixture with PEG 6000 (1:4) where (A) MLX alone, (B) PEG 6000 (C) co-ground mixture (1:4).

\section{Differential scanning calorimetry (DSC) study}

Differential scanning calorimetry (DSC) studies were undertaken to consolidate the IR data explaining the reduction of the crystallinity of MLX with PEG. DSC studies were performed on the individual components and on the freshly prepared coground mixture and results are summarized in Table 2. The DSC thermograms of each component exhibited a sharp endothermal peak corresponding to the melting point of MLX $\left(257.38^{\circ}\right)$, and PEG (61.58 ${ }^{\circ}$ ) (Fig. 8). A difference in heat of fusion of co-ground mixtures and PMs of MLX with PEG indicates a slight reduction in PEG crystallinity. The decrease in enthalpy $(\Delta \mathrm{H})$ value of the co-ground mixture, compared to that of the pure drug, strongly suggests that crystalline drug was transformed at least partly to the corresponding amorphous structure (Table 2). The reduction in 
crystallinity and / or transformation to amorphous structure would be responsible for dissolution enhancement of the drug, in addition to the solubilizing effect of the carrier used. The complete disappearance of the melting endothermic peak of MLX and the observed reduction in enthaply $(\Delta \mathrm{H})$ (Table 2$)$ in ball milled meloxicam co-ground mixture with PEG (1:4) strongly suggests a remarkable reduction in MLX crystallinity by co-grinding technique.

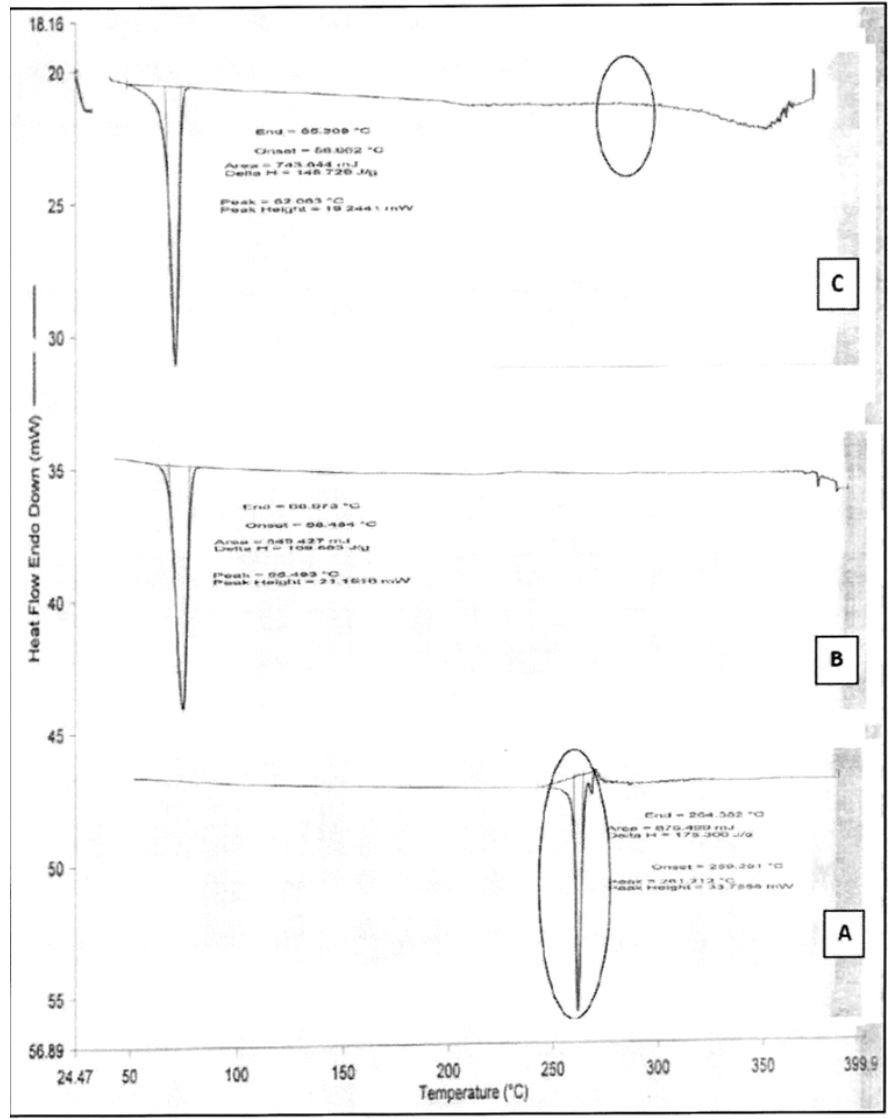

Fig. 8: DSC thermograms of meloxicam (MLX ) alone (A), where: (A) MLX alone (B) PEG 6000 (C) MLX- PEG 6000 (1:4) ball milled co-ground mixture.

Table 2: Differential Scanning Calorimetry (DSC) data of meloxicam (MLX), PEG 6000, and MLX-PEG (1:4) ball-milled (BM) co-ground mixture.

\begin{tabular}{lllll}
\hline $\begin{array}{c}\text { Mixture } \\
\text { components }\end{array}$ & $\begin{array}{c}\text { Mixture } \\
\text { type }\end{array}$ & $\begin{array}{c}\text { Peak } \\
\text { Temp. } \\
\left({ }^{\circ} \mathbf{C}\right)\end{array}$ & \multicolumn{1}{c}{$\begin{array}{c}\text { Melting } \\
\text { range }\left({ }^{\circ} \mathbf{C}\right)\end{array}$} & $\begin{array}{c}\Delta \mathbf{H} \\
(\mathbf{J} / \mathbf{g})\end{array}$ \\
\hline MLX alone & ---------- & 261.212 & $259.29-264.38$ & 175.3 \\
PEG 6000 alone & -------- & 65.493 & $58.48-68.97$ & 169.885 \\
MLX : PEG & BM $(1: 4)$ & 62.063 & $56.62-65.30$ & 148.729 \\
\hline
\end{tabular}

\section{Stability study}

Stability is one of the critical aspects in ensuring safety and efficacy of drug products. Pharmaceuticals should be stable and maintain their quality until the time of usage or until their expiration date (Yoshiska and Stella, 2002). If a drug product is stable enough to be marketed, it would require relatively long storage time at room temperature or actual temperature at which it will be stored prior to ultimate use, to permit observation of the rate at which the product decomposes under normal storage conditions. The design of solid-state stability studies is complicated by the fact that, many solid-state degradation reactions don't follow Arrhenius kinetics. Phase changes (glass transition, crystalline melting, polymorphic changes, solvation/ desolvation) are expected to be radically changed after different degradation pathways (Koenigbauer et al., 1992). Therefore, stress stability studies beyond certain temperature range could induce phase changes, which could alter the validity of the Arrhenius equation. For example, degradation of an amorphous drug is not expected to follow the Arrhenius relationship when its glass transition temperature is crossed (Duddu and Dal Monte, 1997). In addition, reaction mechanisms could change as temperature is changed (Olsen et al., 1997). Therefore, caution must be taken when the effect of temperature on solid-state degradation is studied. Accordingly, the physical and chemical stability of MLX in the tested MLX-PEG containing tablets were performed at room temperature to avoid the above mentioned limitations.

\section{Physical stability}

The tested tablet formulation did not show any change in their appearance (such as color and odor) during the stability study when stored at $25^{\circ} \mathrm{C} / 60 \% \mathrm{RH}$ for 12 months.

In addition, no remarkable changes were observed in the disintegration time, thickness and drug content of the test Meloxicam tablets during storage for 12 months.

\section{Dissolution rate}

Pharmaceutical scientists, e.g. (Moore and Flanner 1996) and (Duan et al., 2011), used the concept of similarity factor and difference factor to compare between dissolution profiles of different dosage forms, rather than comparing the dissolution tolerance limit specified in the Pharmacopeia.

The similarity factor (f2) is a logarithmic transformation of the average of the squared vertical distances between the test and reference mean dissolution values at each dissolution time point. It was evident that the dissolution rate of MLX from the tested tablets was not significantly affected, as indicated by the calculated similarity factor (f2) and difference factor (f1). The observed similarity factor (f2) was 85 (>50) and difference factor (f1) was $2(<15)$, clearly indicates that there is a significant similarity and no significant difference in dissolution rate of the prepared tablets before and after the stability study.

\section{Powder X-ray diffraction pattern}

Figure 9 shows that no changes in the XRD pattern of MLX were found after storage for 12 months, indicating the absence of significant reversion of MLX from its proposed amorphous state to its crystalline state during the period of storage at $25^{\circ} \mathrm{C}$.

The results of stability study of meloxicam tablets prepared using the co-ground mixture with PEG 6000 revealed a proper resistance of the prepared tablets to storage at $25 \pm 1^{\circ} \mathrm{C} /$ 
$60 \%$ RH for a period of 12 months without showing any appreciable change in its properties.

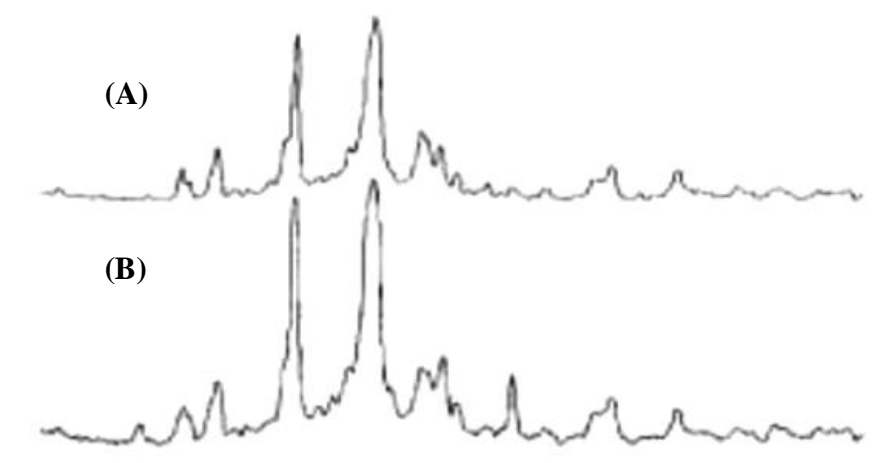

$+1$

Fig. 9: $\mathrm{X}$ - ray diffractograms of the prepared meloxicam tablets before (A) and after (B) storage for 12 months at $25 \pm 1^{\circ} \mathrm{C} / 60 \% \mathrm{RH}$.

\section{In vivo Study \\ HPLC method}

Both the MLX and the internal standard peaks were well resolved and no endogenous interference was observed. Acetonitrile was selected as the organic modifier of the mobile phase as this reagent produces the least base-line noise compared to methanol. Optimal separation was achieved with $60 \%$ acetonitrile in $20 \mathrm{mM}$ potassium phosphate buffer at $\mathrm{pH} 3.5$. The retention times of MLX and IS were approximately 5.75 and 4.53 minutes, respectively.

The mean regression calibration curves were expressed as $y=12.362( \pm 0.27) \mathrm{x}+0.0006( \pm 0.06)$ with the correlation coefficient value $(r)=0.9997$. Based on the SD of the $y$-intercepts and slope of the curves, the LOQ of MLX was estimated to be 100 $\mathrm{ng} / \mathrm{mL}$. Subsequently, repeated analysis with this LOQ (100 $\mathrm{ng} / \mathrm{mL}$ ) revealed a signal-to-noise ratio greater than 10: 1 with a level of accuracy within $20 \%$ and a CV less than $15 \%$. Therefore, $100 \mathrm{ng} / \mathrm{mL}$ of MLX in a $250 \mu \mathrm{L}$ sample volume was identified as the lowest quantifiable concentration of the calibration curve for our study conditions.

Intra- and inter-day precision expressed as CVs ranged from 0.12 to $3.95 \%$ and 0.11 to $3.46 \%$, respectively. Intra- and inter-day accuracy expressed as a percentage of the bias ranged from 0.23 to $2.47 \%$ and 0.14 to $3.78 \%$, respectively. These values satisfied the ICH guidelines (ICH 1996) regarding assay reliability. The absolute recovery rates of MLX from the $(100,500$ and $2000 \mathrm{ng} / \mathrm{ml}$ ) samples were $91.67 \pm 1.49,93 \pm 1.12$ and $92.32 \%$ \pm 1.5 , respectively. The absolute recovery rate of IS was $97.3 \%$

\section{Pharmacokinetic assessment}

The developed MLX tablets were tested for their in vivo performance against a marketed reference product ( $M b c^{\circledR}$ tablets) in six healthy male volunteers. Plasma MLX concentrations at different time intervals for the test and reference product in the individual volunteers were calculated, and the mean values $v s$. time are graphically presented in Fig. 10. The relevant pharmacokinetic parameters including $\mathrm{C}_{\max }, \mathrm{T}_{\max }, \mathrm{K}_{\mathrm{e}}, \mathrm{T}_{1 / 2}$, $\mathrm{AUC}_{0-24}$ and $\mathrm{AUC}_{0-\infty}$ of the test and reference product in the six volunteers are illustrated in Table 3 . The obtained results revealed that, meloxicam tablets containing co-ground mixture with PEG 6000 showed higher $\mathrm{C}_{\max }\left(1.49 \pm 0.58 \mu \mathrm{g} \cdot \mathrm{ml}^{-1}\right)$, higher $\mathrm{AUC}_{0-24}$ $\left(37.56 \pm 1.07 \mu \mathrm{g} . \mathrm{hr}^{\mathrm{m} l^{-1}}\right)$ and higher $\mathrm{AUC}_{0^{-} \infty} \quad(44.637 \pm 1.94$ $\mu \mathrm{g} . \mathrm{hr} . \mathrm{ml}^{-1}$ ), compared to the reference $\mathrm{Mbc}^{\circledR}$ tablets; $1.3 \pm 1.99$ $\mu \mathrm{g} . \mathrm{ml}-1, \quad 28.72 \pm 1.53 \mu \mathrm{g} . \mathrm{hr} \cdot \mathrm{ml}^{-1}$, and $35.3 \pm 1.56 \mu \mathrm{g} . \mathrm{hr} . \mathrm{ml}^{-1}$, respectively.

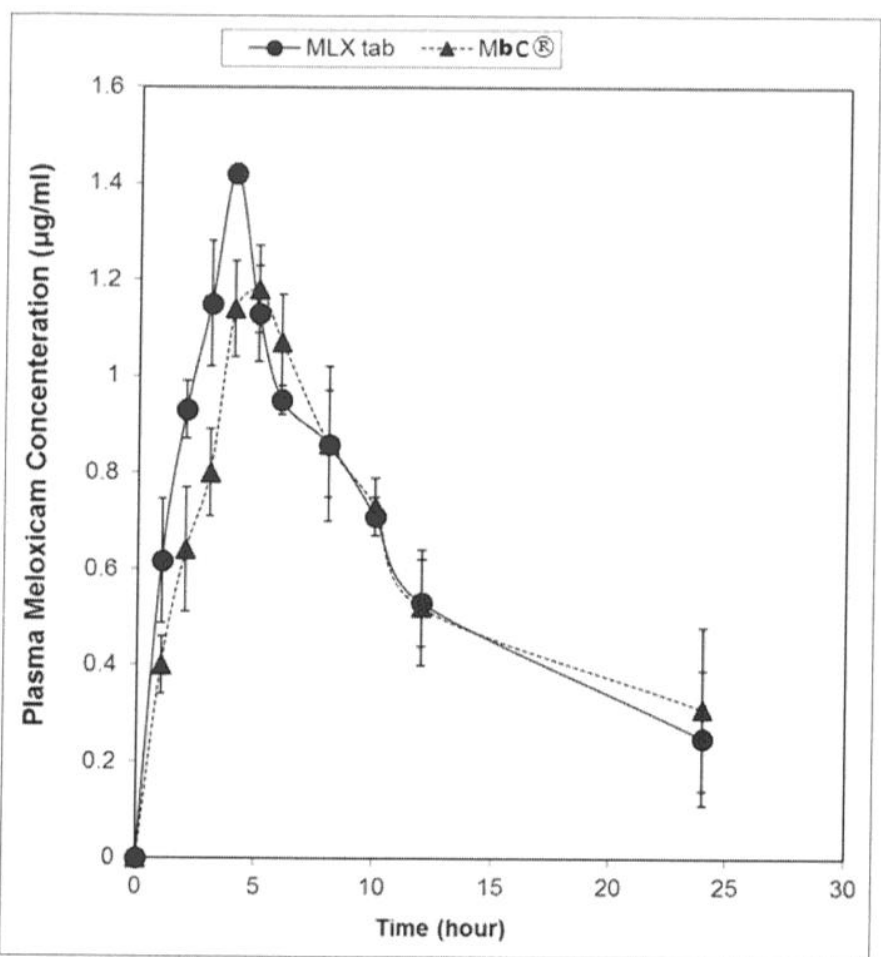

Fig. 10: Mean Plasma concentration time curve of meloxicam following oral administration of $15 \mathrm{mg}$ prepared meloxicam tablets and the reference $\mathrm{Mbc}{ }^{\circledR}$ tablets to 6 healthy human male volunteers.

It could be observed from the results presented in Fig. 10 that the prepared meloxicam tablets showed higher mean plasma concentration in most of the time intervals tested. The mean calculated $\mathrm{T}_{\max }$ of test product was shorter $(4.5 \mathrm{~h})$ than that of the reference one $(5.17 \mathrm{~h})$, which could mean a faster onset of action of the developed product and better control of inflammation and pain.

The calculated MRT of the test product $(7.403 \mathrm{~h})$ was higher than that of the reference one $(6.53 \mathrm{~h})$ which could mean a longer duration of action of the developed product.

Statistical analysis of the results indicated significant differences $(\mathrm{P}<0.05)$ between the developed tablet and the reference product. The $\mathrm{AUC}_{0-24}, \mathrm{AUC}_{0-\infty}$ and $\mathrm{C}_{\max }$ values of MLX from test tablets were higher than the corresponding values of the reference tablets; namely $1.31,1.26,1.15$ folds respectively. 
Table 3: Pharmacokinetic parameters of the prepared meloxicam tablets and Mbc tablets (reference product) in 6 healthy human male volunteers.

\begin{tabular}{|c|c|c|c|c|c|c|c|c|c|c|c|c|}
\hline \multirow{2}{*}{$\begin{array}{c}\text { Volunteer } \\
\text { abbreviation }\end{array}$} & \multicolumn{2}{|c|}{$\mathrm{C}_{\max }(\mu \mathrm{g} / \mathrm{ml})$} & \multicolumn{2}{|c|}{$\mathbf{T}_{\max }(\mathbf{h})$} & \multicolumn{2}{|c|}{ T1/2 (h) } & \multicolumn{2}{|c|}{$\mathrm{K}_{\mathrm{el}}\left(\mathbf{h}^{-1}\right)$} & \multicolumn{2}{|c|}{$\mathrm{AUC}_{0-24}\left(\mu \mathrm{g} \cdot \mathrm{h} \cdot \mathrm{ml}^{-1}\right)$} & \multicolumn{2}{|c|}{$\mathrm{AUC}_{0-\infty}\left(\mu \mathrm{g} \cdot \mathrm{hr} \cdot \mathrm{ml}^{-1}\right)$} \\
\hline & MLX tab & Mbc & MLX tab & Mbc & MLX tab & Mbc & MLX tab & Mbc & MLX tab & Mbc & MLX tab & Mbc \\
\hline $\mathbf{M}$ & 1.471 & 1.256 & 6 & 6 & 21.5 & 22.7 & 0.032 & 0.031 & 40.65 & 30.4 & 49.4 & 39.11 \\
\hline $\mathbf{W}$ & 1.26 & 1.16 & 4 & 5 & 19.8 & 20.4 & 0.035 & 0.034 & 36.1 & 26.3 & 44.243 & 33.4 \\
\hline $\mathbf{S}$ & 1.64 & 1.14 & 4 & 5 & 21.2 & 18.1 & 0.033 & 0.038 & 42.58 & 24.3 & 50.99 & 30.88 \\
\hline $\mathbf{H}$ & 1.23 & 1.24 & 4 & 5 & 17.35 & 19.3 & 0.04 & 0.036 & 34.88 & 31.9 & 42.88 & 38.29 \\
\hline $\mathbf{K}$ & 2.047 & 1.82 & 4 & 4 & 18.2 & 19 & 0.038 & 0.036 & 35.87 & 34.34 & 40.08 & 39.89 \\
\hline $\mathbf{Z}$ & 1.27 & 1.17 & 5 & 6 & 19.1 & 18.9 & 0.036 & 0.037 & 35.3 & 25.1 & 40.23 & 30.24 \\
\hline Mean \pm SD & 1.49 & 1.3 & 4.5 & 5.17 & 19.20 & 20.7 & 0.036 & 0.0335 & 37.56 & 28.72 & 44.637 & 35.3 \\
\hline & \pm 0.58 & \pm 1.99 & \pm 0.55 & \pm 0.82 & \pm 0.64 & \pm 1.05 & \pm 0.04 & \pm 0.05 & \pm 1.07 & \pm 1.53 & \pm 1.94 & \pm 1.56 \\
\hline
\end{tabular}

\section{CONCLUSION}

Meloxicam tablets containing ball-milled co-ground mixture with PEG 6000 in ratio of 1:4 exhibited superior dissolution rate, short disintegration time and good hardness. Dissolution rate of the prepared tablets was higher than the three marketed meloxicam tablets. The observed fast drug release from the developed tablets will provide rapid onset of action and also allow a reduction of drug dose necessary to achieve the therapeutic effect. This, in turn, reduces the most common side effects observed with non-steroidal anti-inflammatory drugs.

The stability study did not show any significant changes in physical appearance of the prepared tablets, drug content, thickness, disintegration time, and dissolution rate during and after the end of 12 months storage period at $25 \pm 1^{\circ} \mathrm{C} / 60 \% \mathrm{RH}$.

The prepared meloxicam tablets showed higher bioavailability, as evidenced by significant higher AUC and significant lower $\mathrm{T}_{\max }$ which could indicate higher extent of absorption and rapid onset of action. The bioavailability of the test developed tablets was $126.45 \%$, relative to the marketed brand product $\left(\mathrm{Mbc}^{\circledR}\right.$ tablets) which will be reflected on better pain and inflammation relief.

\section{Financial support and sponsorship: Nil.}

Conflict of Interests: There are no conflicts of interest.

\section{REFERENCES}

Barzegar-Jalali M, Nayebi AM, Valizadeh H, Hanaee J, Barzegar-Jalali A, Adibkia K, Anoush M, Sistanizad M. Evaluation of in vitro-in vivo correlation and anticonvulsive effect of carbamazepine after cogrinding with microcrystalline cellulose. J Pharm Pharm Sci, 2006; 9(3):307-316

Blagden N, de Matas M, Gavan PT, York P. Crystal engineering of active pharmaceutical ingredients to improve solubility and dissolution rates. Adv Drug Deliv Rev, 2007; 59(7):617-630.

Duan JZ, Riviere K, Marroum P. In vivo bioequivalence and in vitro similarity factor (f2) for dissolution profile comparisons of extended release formulations: how and when do they match? Pharm Res, 2011; 28:1144-1156

Duddu SP, Dal Monte PR. Effect of glass transition temperature on the stability of lyophilized formulations containing a chimeric therapeutic monoclonal antibody. Pharm Res, 1997; 14:591-595.
Engelhardt G, Homma D, Schlegel K, Utzmann R, Schnitzler C. Anti-inflammatory, analgesic, antipyretic and related properties of meloxicam, a new non-steroidal anti-inflammatory agent with favourable gastrointestinal tolerance. Inflamm Res, 1995; 44:423-433.

Etman M, Shekedef M, Nada A, Ismail A. Reaparation and invitro evaluation of meloxicam co-ground mixtures. $6^{\text {th }}$ World Congress on Bioavailability \& Bioequivalence: BA/BE Studies Summit August 17-19, 2015 Chicago, USA. [ONLINE] Available at: http://www.omicsonline.org/proceedings/preparation-and-invitro-

evaluation-of-meloxicam-coground-mixtures-31050.html [Accessed 20 September 2016].

Gibaldi M. 1991. Biopharmaceutics and Clinical Pharmacokinetics Philadelphia, London: Lea \& Febiger.

Grau MJ, Kayser O, Müller RH. Nanosuspensions of poorly soluble drugs--reproducibility of small scale production. Int J Pharm, 2000; 196:155-159.

ICH harmonised tripartite guideline, Validation of analytical procedures: text and methodology Q2(R1), Geneva, 2005.

Ji HY, Lee HW, Kim YH, Jeong DW, Lee HS. Simultaneous determination of piroxicam, meloxicam and tenoxicam in human plasma by liquid chromatography with tandem mass spectrometry. J Chromatogr B Analyt Technol Biomed Life Sci, 2005; 826:214-219.

Koenigbauer MJ, Brooks SH, Rullo G, Couch RA. Solid-state stability testing of drugs by isothermal calorimetry. Pharm Res, 1992; 9:939-944.

Moore J, Flanner H. Mathematical comparison of dissolution profiles. Pharm Technol, 1996; 20:64-75.

Olsen BA, Perry FM, Snorek SV, Lewellen PL. Accelerated conditions for stability assessment of bulk and formulated cefaclor monohydrate. Pharm Dev Technol, 1997; 2:303-312.

USP 2011, The United States Pharmacopeial Convention, Rockville, MD, USA

Velpandian T, Jaiswal J, Bhardwaj RK, Gupta SK. Development and validation of a new high-performance liquid chromatographic estimation method of meloxicam in biological samples. $\mathrm{J}$ Chromatogr B Biomed Sci Appl, 2000; 738:431-436.

Yoshiska S, Stella VJ. 2002. Stabilization of drugs and dosage forms Kluwer academic publishers.

\section{How to cite this article:}

Etman MA, Shekedef M, Nada AH, Ismail A. In Vitro and In vivo Evaluation of Tablets Containing Meloxicam- PEG 6000 BallMilled Co-Ground Mixture. J App Pharm Sci, 2017; 7 (03): 031039. 